\title{
Progress in Aerial Sketching of Forest Arecio
}

\author{
By F. T. JENKINS,
}

Managing Director, James D. Lacey \& Co. (Canada) Limited.

The paper which I am about to read is meant to show mainly, the different uses of aerial sketch maps, and is based on personal experience since the early stages of aerial mapping. The origin and development of aerial sketching have been covered previously.

Aerial Sketch Mapping is a comparatively new art. It has been in existence for six or seven years. Perhaps it is not generally known that in this time, approximately 120,000 square miles in Canada have been mapped by the Aerial Sketching Method. This does not include photography.

ปิ By bringing back reliable information on vast northLern areas, it has done much to disillusion us as to un\#imited supplies of softwoods, and to establish a sounder working basis for forest policies. If this were all, ft has been justified, but it has also saved many thousands of dollars and a great deal of time to those activeHy interested in forest inventories.

It should be explained that an aerial forest sketch Imap is not a standardized product, any more than is a forest survey map made from data collected on the round. It shows essentially the same features, forest thypes, etc., and the amount of detail is controlled by the same principal factor, namely, the cost appropriaHon. Sometimes the form of map that will best serve the special purpose desired is obtained, but usually tise money allowance makes it necessary to dispense W.th some detail. The sketch work is done by a speeqflly trained forester, during the flights. He directs the course of the machine by a set of pre-arranged sigThals between himself and the pilot and sketches the grequired detail on the best available map of the disgrict, enlarged to a convenrent scale and mounted, in sections, on beaverboard. If the original map is aceuate and reasonably detailed as to topographical inFormation, the sketch work is simplified and a very Treliable and detailed forest type may be produced by a skilful sketcher. If the base map is not reasonably Gdetailed the accuracy of the sketch will be reduced and the types broader. So, these are additional factors Fontrolling the class of work done.

The main advantages over ground work are the speed of production, and low cost. From 30 to 300 Isquare miles may be mapped in one hour, depending upon the class of work required. The cost varies from $\$ 10.00$ to $\$ 1.50$ per square mile. This is many times cheaper than any known ground method, and puts the work within the reach of every forest owner.

To bring before the public the need of forest conservation, we must first show how much raw material is available, as well as the annual consumption and prowth. Since forest inventory is the first step in this direction, and good maps are very advantageous, it haturally follows that an aerial forest sketch map, quickly produced at low cost, may be recommended as an asset to any forest inventory. While the aerial forest map does not substitute the ground survey, berause it does not give an estimate of quantitios and growth of various species, the report accompanying

'Paper read before the Canadian Society of Forest kingineers' Annual Meeting, 1927. it gives a description of the relative value of the various types. A good map is essential for proper forest protection, and forest protection is an important factor in conservation so aerial maps are doubly important. Most of the limits in Eastern Canada are very extensive, running sometimes to thousands of square miles. Before establishing any definite forest policy, a reliable map of the area under consideration is a practical necessity, if efficient plans are the objective. Ground forest surveys are comparatively slow and expensive, though, when completed, give other necessary information. It has, however, been demonstrated that an aerial sketch map, available before the ground survey is projected, saves in the total expenditure for the combined survey, because much time can be saved by a foreknowledge of canoe routes and locations of burns, waste and forest areas. A great additional advantage lies in having the map immediately as a basis for definite protection plans, which would otherwise be delayed for perhaps several years until the data gathered by ground parties has been plotted in map form. It, therefore, supplies the necessary information for fire protection at once and lessens the cost and time of the ground survey.

Just what kind of a sketch map is produced depends upon controlling factors already mentioned. Each problem must be studied separately. An aerial forest sketch map should be made of every extensive property, if it has not already been well mapped. Just what detail should be included depends upon factors, differing in each case. On small properties, it is sometimes impracticable.

A few of the special uses which have proved of practical value are:

(1) Aerial Reconnaissance for exploring the timber resources of unknown districts. This is the cheapest and quickest method known. The initial investment, to find whether the area in question is worth while looking over on the ground, is low, so the investigator stands to lose little.

(2) To map the boundary of a recent burn. A reliable, rapid and cheap method.

(3) To check up type areas on properties cruised many years ago.

(4) For Government exploration of the resources of vast areas.

(5) To provide a map for forest protection purposes.

(6) As a preliminary to a ground reconnaissance or forest survey

(7) To check up cut-over areas.

In our experience in commercial work, we have found that a proper correlation of air and ground work is effective. By using a sketch map, we get away from at least one of the doubtful factors in ground surveys, namely, forest type areas. It seems to me that to have a forest type map, previous to the ground survey, is the logical way to go at a cruise. The old methods of cruising, whereby we plow through the woods taking measurements at intervals and trust- 
ing to the good old standby "law of averages" for results, works fairly well as regards types, when strips are close enough together, but for reconnaissance and semi-intensive surveys, there is room for error. The cruiser travels through the forest like an ant through a forest of grass and sometimes has about as much chance to see the surrounding country. The only difference is that an ant goes up one side of an obstacle and down the other, whereas most cruisers prefer to go around trees. In speaking of cruisers in this irreverent manner, I do not mean to eriticize. They usually haven't a chance, but if an aerial forest type map is available, the cruisers' work is supplemented effectively, and results are more reliable.

In 1924, James D. Lacey \& Co. (Canada) Limited added to their forest engineering service, Aerial Forest Mapping by the Sketching Method and the purpose of ithe following outline is to place before you our recomOmendations for using these maps in ground cruising, fbased on our experience and the experience of our clients. In 1924, the year we first undertook aerial mapOping, we sketched approximately 3000 square miles in oquebec and Ontario. In 1925, our aerial mapping conItracts covered 5000 square miles in Nova Scotia and Quebec. During the 1926 flying season, we mapped ffrom the air 22,000 square miles in Quebec, Ontario fand Manitoba - an increase on the figure for 1925 $>0$ f 340 per cent.

The detail we obtain in aerial sketching depends on the object our client has in mind, the amount of money it be spent and the ground control available. We do Tot contend that our maps are absolutely accurate or the scale, nor do we state we can map all areas Detually well. With a given amount of ground control fand with lakes numerous enough and large enough to on flying comparatively safe, we will undertake to get about the same detail anywhere in Eastern CanDefla. As to accuracy, our maps are relatively accurate Fand that is the most that is ever accomplished in forEst surveying. Topographic features, as mapped by ous from the air, can be readily adjusted when addiAtional control is obtained and the final composite map $\stackrel{\circlearrowleft}{\circlearrowleft}$ ill be more accurate and more detailed than can Jbe obtained by any other method or methods, with Ecomparable costs.

Our classification of Aerial Forest Type Maps is Droad and, due to the variables mentioned above, there Dैare variations in the intensity of surveys of different ocalities. The three general types of Aerial Surveys Eare :

(1) General Aerial Reconnaissance.

(2) Aerial Reconnaissance.

(3) Aerial Forest Survey.

General or Preliminar!y Aerial Reconnaissance

An aerial forest type map under this heading is the cheapest, quickest and least detailed. We take a map showing all the available control and sketch on the broad forest types. No detail in types or waterways is attempted and lakes and streams mapped are done roughly to give the client a general idea of the "lay of the land." The forest types classified are very general and extensive.

Merchantable Timber Types.

Softwood

Mixed

Hardwood

Burn

Barrens and Muskegs
This type of aerial survey is a cheap means of quickly obtaining a general idea of the forest cover on a tract. The map shows whether the area is timbered, burned over or muskeg, and where timbered, broad classifications, based on merchantable value, are made. If more detailed information is required, a more intensive survey is necessary. For the purpose of securing a general picture of a property, before even considering the purchase of a tract, this class of work is of great value. Such a survey would cost but a small fraction of a cent per acre and if a purchase is even thought of, it is a very low preliminary investment.

\section{Aerial Reconnaissance}

When ground control is relatifely scanty and a detailed ground survey is to follow the air work, this type of aerial sketch map is very valuable. Control is sufficient for relatively accurate work and the detail obtained may be expected to consist of:

(a) Main waterways and drivable tributaries.

(b) The larger lakes.

(c) Forest types-as a rule, we adopt the forest type classification used by the client. The types are somewhat broader than ground work would give, in mixed types particularly, where small stands of softwood and hardwood occur. The map used in the air is on the scale 2 miles to the inch because minute detail is not required.

A ground cruising party going into this sketch area will find the map invaluable. It gives considerable information which will greatly facilitate the moving in of supplies and personnel, and the most efficient system for covering the tract can be worked out in detail.

As the cruise proceeds, additional reliable control is obtained and the problems of adjusting the air man is encountered. As stated above, we do not contend that aerial sketching is absolutely accurate, but if properly used, the resulting map is more detailed than a map made by ground methods alone. In adjusting the topographic detail on an aerial sketch map, the following points should be borne in mind, and adjustments made with these factors in view:

(1) Lakes and streams are sketched by comparison to features already mapped. Therefore, if a cruise line, run from a carefully measured base line, strikes a lake out of position, the adjustment is as follows: determine the feature on the aerial map which represents the one encountered, and bring this feature into its proper position. Remembering the system of mapping, shift the features in the vicinity of the feature moved into the same relative position as shown on the sketch map. Care and judgment is necessary in this adjusting, for we cannot state just what features nearby must be moved with the feature accurately located. This will depend on the position of the nearest control, for all topography is mapped using the existing control as correct.

(2) Lakes may be found slightly off-scale, but in making adjustments for length or breadth, the outline of the lakes should not be changed. We believe that looking down on a lake from above, we can get a more accurate outline than a man can get standing on the shore, or, in the winter, by even walking out on the lake.

(3) Lakes may be found lying slightly in the wrong direction. This is to be expected in aerial reconnaissance, for aircraft do not fly in straight lines. Air currents, or "bumps" and wind may cause the machine to swerve to right or left without the 
noting the fact and, as a result, a lake may be mapped with its axis slightly to the right or left of its true position. However, lakes should not be changed in size, shape or direction until the cruiser is absolutely sure that the feature is not accurate on the sketch map.

(4) When topographic features are adjusted, the types in the vicinity must be moved accordingly, for the forest type boundaries are mapped with reference to the topographic features.

(5) Many small lakes, under 1-4 mile in length, will not be shown on the sketch map. In an aerial reconnaissance of this nature, time will not permit the accurate mapping of all the small lakes.

(6) Small streams will be found which are not shown on the map. Many of these streams cannot be seen from the air and, even if they could be seen, sufficient time is not available to map them.

\section{Aerial Forest Survey}

Where available ground control is good, we undertake to map forest areas from the air with about the \$ame degree of accuracy as is obtained by ground methods of survey. All lakes, irrespective of their tize, are mapped. The main waterways and drivable tributaries are sketched, and numerous smaller streams Care mapped. We undertake to map in the forest types, fising the type classifications which our client uses in ground work, if this is desired. The types mapped in this class of aerial work are in greater detail than those on aerial reconnaissance work, and very small inds of softwood can be accurately located. The nap used in the air is on the scale of one mile to the Inf h, so the detail in the outline of lakes will be greatEte than on reconnaissance work. In other words, an Aerial Forest Survey is detailed - the other types of arial sketching are comparatively general.

When the ground cruise finds adjustments in the gुoation or size of topographic features, the same proCedure as stated under Aerial Reconnaissance may be adopted. It is to be expected, and correctly so, that annaccuracies on an Aerial Forest Type Map will be smaller and less numerous than on Aerial Reconnaissance maps. The reason for this is obvious:

(a) The ground control is in greater detail.

(b) More money is spent per square mile and, consequently, the sketcher has more time at his disposal for refinements.

Northern Ontario, where township lines have been irun every six or nine miles, and where many rivers and lakes have been traversed, is ideal country for this class of aerial mapping. In parts of Quebec, the ground control is sufficient to justify an Aerial Forest Survey and the results will be very satisfactory. Nova Scotia, where practically all the rivers and lakes have been traversed, is the sketcher's Paradise. Under such conditions as exist there, we can do practically perfect work and the results will surpass the most optimistic expectations.

The instructions above are given with the idea in mind that the territory sketched is going to be cruised by the usual ground methods. As a result of our experience and the experience of our clients, modifications on the usual ground cruising system, so as to take full advantage of the aerial surveys, are very advantageous under certain conditions. In a 1 per cent cruise, recently carried out by one of our clients in Ontario, the use of our aerial forest survey map, supplied them previous to the ground cruise, saved over 1-3 of their usual cost. The conditions follow: A skeleton map, showing lakes and streams on township boundaries, with some interior waterways, was given us. Township boundaries were six miles apart and could usually be seen from the air. We sketched the specified area intensively and furnished our elients with a map complete as to waterways and forest types. Our report described each forest type as to composition, and density and classified the merchantable timber as good, medium, or poor. Reproduction types were described and the average approximate height given.

By a careful study of this information, before the ground work was commenced, the relative intensity of strip or sample plot work was determined for each type. The field parties were organized and instructed to carry out pre-determined work in each type, according to its importance. Some compass lines were run and tied to known points to check the correctness of waterways and type boundaries. The check showed that the sketch map was probably correct. Boundaries of types remained as sketched and if the cruiser considered the type boundary was incorrect, he was instructed not to change it, but to mark on his tally sheet where the sketcli map showed the type boundary. Plots or strip tally within the boundary should then give a fair average for the type. This is logical, because no two cruisers would form the same conclusion as to the exact dividing line between two types, unless the type boundary were very sharply defined. The cruiser on the ground can often see only that part of the type which he is entering, which may give him a false impression of the position of the type boundary elsewhere. On the other hand, the aerial sketcher sees the whole type as a unit, with the various irregularities of boundary, and is in an advantageous position to judge where the boundary should be drawn, if there is a gradual transition from one type to another.

In using this system, an important saving is involved in time, labor and expense, because the stripes may be run from canoe routes as sketched, in whatever direction is necessary, either to ascertain minor topographical conditions or a reliable volume estimate of the type. The system can be modified to meet special requirements of individual forest surveys, and is strongly recommended, when the control is such that an aerial forest survey may be carried out.

When control is fair, but not sufficient to permit such accuracy as in an aerial forest survey, and results of a standard forest survey are desired, we would recommend an aerial reconnaissance to assist as previously outlined, but when it is desired to obtain a reliable estimate in a short time, the following procedure is recommended. Determine first whether there is enough control to make a reasonably accurate Aerial Forest Survey of the area to be examined. This question should be submitted to the judgment of an experienced aerial sketcher. Assuming there is sufficient control, sketch the area as intensively as possible. With this map and the descriptive report, plans can be projected in the office before the field parties leave, and the location of strips marked on the cruisers' maps. An immense amount of time can be saved in the field because :

(1) Canoe routes are shown.

(2) Relative values of types are given, and the proper proportion of work spent on each.

(3) Burns can be avoided if desired, 
And in the field because:

(1) Map is already complete when field parties return.

(2) Type areas are already computed.

All that remains then is to apply the average per acre figure, as shown by the strip tallies, to respective types. The office compilation consists only of summarizing compilation sheets and writing the descrip- tive report. There is a saving both in field and office time, resulting in reduced costs.

In point of accuracy, the method is an improvemen on purely ground reconnaissance, because, even thougk type boundaries may be out a little on the aerial mar (if control is poor) they will certainly be more accurat than those plotted from strips run at wide intervals or the ground.

\section{New Methods in Forest Fire Protection}

In the last fifteen years, a great deal of thought has been given to the problem of forest-fire protection, and much work has been done. Lookouts and flephone limes have been cortstructed; aeroplanes enpipped with radio to communicate with ranger staEons have been used for detection; fast motor transfort has been used to rush men to the scene of the Hutbreaks; and for suppression, new fire-fighting $\$ 0$ ss have been developed, and portable pumping efuipment of various types has been made available. All these various factors have been brought into ase with a view to cutting down the time elapsing Hetween the outbreak of a fire and the time of contool. Furthermore, we have been gathering data on orlative humidity, in cooperation with the MeteorAुggical Service, in the hope that we may be able to fore forecasts of fire weather far enough in advance Enable organizations to make plans, both to be ready two attack fresh outbreaks quickly, and to deal more 界实lligently with those already under way.

审here have been few developments recently that I ôtion of in organization and the use of personnel. I might mention, however, that in Northern Alberta, \&lipe we have had a purely seasonal force, we have fis und it advantageous to keep on a small skeleton sfaff of our rangers during the winter months. Hese rangers cover wide territories, to get in touch Fith trappers and follow up the winter routes of teighters and travelers, and handle winter camp fires. If have found that these winter camp fires are a tuitful cause of spring conflagrations, having smoldered in the ground throughout the remainder of the inter season. Many of the points where these hangfiger fires are left could be reached only with great Iffficulty in the summer. Our rangers kept on for inter, also go over the fires of the previous summer, thd dig ont ground fires that might give further trouble during the next fire season.

Those of you who have been interested in active fire protection for a number of years will, I am sure, agree with me that there is a tendency to look with disfavor on the ideas brought forward by the other organizations without giving them a fair trial. For instance, I doubt not that when the gasoline fire-fighting pump was originally advocated by the pioneers in that line, there were some skeptics who, without even seeing the pumps in action, decided at once that they would be of no particular use in their districts. I don't doubt that these pessimists laughed at the pumps as not being sufficiently portable, not realizing that this was only the germ, and that it would be developed. Some, I am sure, laughed at the pump because they thought that water would not be available close to the fire, little knowing how far water would eventually be forced to fire outbreaks. Now every forest organization of any importance uses pumpins equipment whenever the chance occurs. In fact, pumps have sprung into such universal use that it has be. come the usual thing to take along a pump to a fire as a matter of course, on the chance that it can be used. It usually can.

All forest officers should keep an open mind with respect to new developments in equipment, and shoulc be willing to give them fair trial at least, before pass. ing judgment. We must not be provincial in our out look on new ideas advocated.

The past year has seen a great development in nen types of gasoline pumping equipment. The most out standing development is the placing on the market of the extremely light, twin-cylinder pump; this pump lias proved a great success during the past season By the use of opposed cylinders, vibration is almos eliminated, with the result that repairs are reduce to a minimum. The pump is particularly useful to $u$ in the mountains where portability is one of the mair features to be considered. One can put a pump o: this sort on each side of a horse, and then have nc more than a comfortable pack.

Another development in pumping equipment is thi type of pump taking its power from the front end 0 : automobile engines. There are at least two makes 0 : these pumps on the market. With their greater pow er and capacity, they would be of great advantagi in relaying water to points where the smaller portabl pumps could be set up to pump direct to the fire They should be capable of delivering water to greate: elevations than the smaller portable pumps. An ad vantage of the car engine as a source of power is tha it may be kept running at full capacity without th attention that it is necessary to give to small pumpin units. An automobile engine will stand a great man! hours of heavy duty. There is also the advantage tha motor-car equipment with front end pump attach ments, can be used as a means of transportation whes not required as pumpers. These pumps have, how ever, a limited field of usefulness. They, of course can only be brought into action where water is avail able along roads. They are rather costly when on considers that there is only the pump itself to be pro vided and on engine. They are, as yet, rather heav: and awkward, and there will have to be improvement and refinements before they come into general use There is a pump, however, in the course of develop ment by our service, which is of smaller capacity ani which only weighs about thirty pounds complete The pump is so light and compact it may be carrie 